\title{
Optimal Use of Energy Storage Systems with Renewable Energy Sources ${ }^{\text {th }}$
}

\author{
Alberto J. Lamadrid ${ }^{1, *}$
}

\begin{abstract}
This article proposes a multi-period optimization to study the technical and economic effects of the placement and use of renewable energy sources (RES) and Energy Storage Systems (ESS) in an electrical network. As the RES penetrations increase, their inherent variability will decisively affect the actual amounts of energy dispatched, their contribution to decrease emissions of pollutants and greenhouse gases, and the overall welfare effects they may have. Moreover, to better harness the energy from renewable sources, both new methodologies and technologies need to be adopted, counteracting the variability and uncertainty of these sources. A possible solution to the challenges of RES adoption is the coupling to energy storage sources, either as dedicated facilities on the supply side, or supporting the accommodation of loads to the available generation on the demand side. This paper suggests an algorithm for network dispatch, aimed at answering some of fundamental changes in the way the system is managed and discusses analytical characteristics of the optimal solution.

The proposed methodology is applied to a case study. Four scenarios are analyzed in their dispatches, estimating the welfare effects on the participants in the wholesale market for a modified IEEE 30-bus network with wind energy as the RES in penetrations close to $15 \%$. The policy implications from the results obtained prove that, first, ESS can decrease the ramping necessary for load following, but not necessarily increase the amount of wind energy used, and second, congestion patterns in the electrical network play a crucial role in the final effectiveness of the RES and ESS. These are important insights into an ongoing debate on how to direct storage and renewable energy investments for a low carbon economy.
\end{abstract}

Keywords: Optimal Power Flow, Mixed Integer Programs, Lagrangian Relaxation.

\footnotetext{
This research was supported by the US Department of Energy through the Consortium for Electric Reliability Technology Solutions (CERTS) and by the Power Systems Engineering Research Center (PSERC).

${ }^{*}$ Corresponding Author

Email address: ajlamadrid@lehigh.edu (Alberto J. Lamadrid)
}

Preprint submitted to International Journal of Electrical Power \& Energy SystemsFebruary 24, 2015 


\section{Introduction}

The windy shores of Lake Erie will have one of the first demonstration projects of a new technology that may become ubiquitous. A 32 MW Vanadium Redox battery will be placed in the city of Painesville, $\mathrm{OH}$, in a symbiotic role with an existing coal plant. This pilot joins projects being conducted in the US and in other countries to better understand the role and placement of Vanadium Redox and other energy storage systems (ESS) and technologies to manage the electricity network $((1 ; 2))$.

To maintain Operating Reliability (e.g. (3)), system operators are required to adopt practices that use new available technologies. The interest in storage technologies and ESS for electricity network operations stems from fundamental changes occurring in the way these complex systems are managed. In different countries, the amount of energy from renewable sources is increasing, either by market forces or voluntary quotas, like Renewable Portfolio Standards in the US (4). The system operation needs to better accommodate the power delivered by stochastic sources, without compromising the security of the system, as has been well documented (e.g. $(5 ; 6))$.

As new Energy Storage Systems (ESS) technologies like the Vanadium Redox flow battery are developed, their active participation in future power systems are likely to witness a significant increase $((7 ; 8 ; 9))$. This is driven by different forces, like cost reducing technology advancements and the expected forthcoming of electrified transportation in urban centers. While dedicated ESS capacity is already in use for certain systems (e.g. Sodium sulfur, (10)), its prohibitive cost has not allowed widespread coupling with intermittent generation sources. The electrification of transportation on the other hand provides an opportunity to develop compensation mechanisms that encourage vehicle owners to participate in the energy and ancillary services markets, providing further ESS capacity from the car's chemical storage $((11 ; 12 ; 13))$.

This paper suggests a formulation for a multi-period Alternating Current Optimal Power Flow (AC-OPF) to analyze the interaction between Renewable Energy Sources (RES) and ESS optimal usage. The analytical model is illustrated with a case study focusing on the effects of location and geographic distribution of both resources.

The paper is structured as follows: Section 2 synthesizes the antecedents to this work and presents the analytical framework. Sections 3 and 4 summarize the specifications of a case study that considers the effects of location for RES, specifically wind, and for ESS in an electrical network. Section 5 analyzes the obtained results and the conclusions are summarized in Section 6.

\section{Literature and Problem Formulation}

The antecedents to the engineering network problem in this article can trace its roots back to the seminal economic dispatch and Optimal Power Flow (OPF) contributions by (14). Later research has extended this model to include welfare considerations that allow for optimal load shedding, in the framework of 
support for ramping service provision ((15)). The issue of proper provision of ancillary products is discussed in (16), with special attention paid to the necessity of a clear remuneration structure to ensure adequate quality of service in the Australian New Electricity Market (NEM). Part of the philosophy of NEM is cost causality. ${ }^{1}$

The adoption of RES in the system, specifically wind, is studied in (17) with a wind model that assesses the reliability contribution of a wind farm. The methodology is comprehensive, while recognizing the high level of data requirements for proper calculation. Such high data input requirements are a generalized issue that can limit the usability of agents with constrained data. ${ }^{2}$ The study of the capacity contribution of RES such as wind is a subject of continued debate. In general terms, the support provided by wind generation is dependent on the characterization of the resource, and its relation to the demand in the system $((19))$.

(20) study a single node problem with heterogeneous consumers that could be curtailed in their demand, according to assumed price-sensitivity preferences assigned using a scaling factor. Their question is planning-oriented, finding the optimal level of investment to cover the electricity demand, and establishing the outputs and price schedules expected. Their results provide a stylized benchmark to compare regulatory schemes.

The aim of this model is to provide an engineering-economic framework to evaluate the use of storage resources as optimized by a social planner, in the context of high penetrations of Renewable Energy Sources (RES) in the electricity system. The uncertainty in the system, coming from RES is modeled as a gaussian noise in each period that affects the availability of RES available (21).

The main contribution of this work is the suggest a method that includes specific restrictions reflecting the technical (engineering) characteristics of the electricity network, and endogenously solves the optimized dispatches for ESS, for all generating units and for dispatchable demands, taking into account the economic and dynamic characteristics of each element. Such considerations are necessary to reflect the true benefits (and costs) faced by a System Operator, the congestion that can lead up to the formation of load pockets $((22))$, and the effects that adoption of RES has in the system. I derive optimality conditions for the trade-offs between conventional generators and ESS resources for the case in which the commitment decisions are set (23). To the best of my knowledge this is the first paper to include a complex model of the attributes of the network and the analytical derivation of inter-temporal tradeoffs of using an ESS unit. The implementation uses MATPOWER's extensible architecture (24), with a case study to illustrate the use of the methodology.

\footnotetext{
${ }^{1}$ Participants in energy markets should be paid for providing, and pay for the energy services they use.

${ }^{2}$ System Operators generally have such information; but in such case, the relevant question is the proper market design to elicit the necessary information (18).
} 


\subsection{Multiperiod AC-OPF}

Consider a social planner (a System Operator -SO), maximizing the total welfare in the system of providing energy subject to reliability economic criteria and the non-linear constraints of an OPF AC system (14; 25). In addition to the OPF variables, the $\mathrm{SO}$ is faced with the decision of which units to commit in advance, the "unit commitment" (UC) problem ((26)). The general form for this combined problem is as follows:

$$
\min _{\mathbf{x}, \mathbf{p}, \mathbf{e}, I} f(\mathbf{x}, \mathbf{p})+C(\mathbf{p}, I)+f_{u}(\mathbf{x}, \mathbf{p}, \mathbf{e})
$$

subject to

$$
\begin{gathered}
g(\mathbf{x}, \mathbf{p}, \mathbf{e})=0 \\
h(\mathbf{x}, \mathbf{p}, \mathbf{e}) \leq 0 \\
\mathbf{x}_{\min } \leq \mathbf{x} \leq \mathbf{x}_{\max } \\
0 \leq \mathbf{p} \leq \mathbf{p}_{\max }^{c} \\
\mathbf{e}_{\min } \leq \mathbf{e} \leq \mathbf{e}_{\max } \\
l \leq A\left[\begin{array}{l}
\mathbf{x} \\
\mathbf{p} \\
\mathbf{e}
\end{array}\right] \leq u
\end{gathered}
$$

The variables for this problem are shown in table 1 .

Table 1: Definition of variables and terms for Aggregating agent

\begin{tabular}{lll}
\hline Variable/Term & & Definition \\
\hline $\mathbf{x}$ & $:$ & Vector of bus voltages and angles \\
$\mathbf{p}$ & $:$ & Vector of real and reactive outputs for generating units \\
$I$ & $:$ & Vector of binary variables indicating which of the $p$ units are de- \\
& & committed from system \\
$\mathbf{e}$ & $:$ & Vector of real (and possibly reactive) outputs for ESS units \\
$f(\cdot)$ & $:$ & Cost Function for real and reactive power \\
$C(\cdot)$ & $:$ & Startup and shutdown costs/benefits \\
$f_{u}(\cdot)$ & $:$ Cost Function including ESS units, real (and possibly reactive \\
& $:$ Set of equality constraints (e.g. non-linear nodal power balance \\
$g(\cdot)$ & $:$ Set of inequality constraints (e.g. branch flow limits as non-linear \\
& $:$ functions of the bus voltage angles and magnitudes). \\
$h(\cdot)$ & $:$ Matrix of additional constraints for voltage's angles and magni- \\
$A$ & $:$ Lower, and real and reactive power. \\
& $:$ Upper limit for additional constraints \\
$l$ & &
\end{tabular}


The cost $f(\cdot)$ is assumed to be separable over units, so the cost of running one unit does not affect the cost of running another one $((27))$. The cost per generator, $C(\mathbf{p}, I)$, is a function of the units committed to the system.

Each one of the constraints can be summarized as follows:

1. The equality constraints (2) consist of the set of non linear power balance equations for real and reactive power for each generator, and ESS constraints, among others.

$$
\begin{aligned}
& g_{P}(\Theta, V, P)=0 \\
& g_{Q}(\Theta, V, Q)=0
\end{aligned}
$$

2. The inequality constraints (3) consist of the set of branch flow limits as non-linear functions of the bus voltage angles and magnitudes, among others.

$$
\begin{aligned}
& h_{f}(\Theta, V) \leq 0 \\
& h_{t}(\Theta, V) \leq 0
\end{aligned}
$$

3. The unit limit constraints, (4) - (6) indicate the upper and lower limits for voltage magnitudes, bus angles and real and reactive generator injections for the committed units. The limits are given by the physical characteristics of the generators and the operational limits for voltage magnitudes and angles. Note that the negative sign for $e_{i}^{t}$ in the case of energy storage units would add to the load to be served.

4. Equation (7) includes additional inequality constraints to (3). They reflect the ramping constraints, e.g. (15)-(16), and the charging and discharging restrictions for ESS units, (17)-(21), among others.

5. Integer variables are used for implementing minimum up and down times for a linearized version of the problem (Direct Current, or DC-OPF). The constraints are:

$$
\begin{gathered}
s_{i, t}-h_{i, t}=u_{i, t}-u_{i, t-1} \\
\sum_{y=t-\tau_{i}^{+}}^{t} s_{i, y} \leq u_{i, t} \\
\sum_{y=t-\tau_{i}^{-}}^{t} h_{i, y} \leq 1-u_{i, t}
\end{gathered}
$$

Where $s_{i, t}$ is a binary variable indicating if unit $i$ was started up in period $t, h_{i, t}$ is a binary variable indicating if unit $i$ was shut down in period $t$ and $u_{i, t}$ is a binary variable indicating if unit $i$ was up in period $t$.

The time horizon is a parameter, so this can be used as an operations and a planning tool.

Starting from a standard OPF problem for a system with $n_{b}$ buses, $n_{g}$ generators and $n_{e}$ ESS units in the system, the implementation of the multiperiod OPF involves variable duplication for the number of time periods considered, $n_{t}$. 
This creates a system with $n_{t} \cdot n_{b}$ buses, $n_{t} \cdot n_{g}$ generators and $n_{t} \cdot n e$ ESS units. All generating and ESS units were constrained by physical ramping limits:

$$
\begin{aligned}
& -r_{g}^{i} \leq p_{t}^{i}-p_{t-1}^{i} \leq r_{g}^{i} \\
& -r_{e}^{i} \leq p_{t}^{i}-p_{t-1}^{i} \leq r_{e}^{i}
\end{aligned}
$$

The ramping constraints are added to the $A$ matrix, and the ramping limits were added to the $u$ and $l$ vectors in (7). No spinning reserve requirements are included. ${ }^{3}$

\subsection{ESS Units}

The ESS units are modeled like generators, with the possibility of having negative real power injections $\left(p_{t}\right)$ for charging periods. It is assumed that only active power can be provided. ${ }^{4}$ Each ESS is modeled as a single unit with both positive maximum $\left(u_{e}\right)$ and negative minimum $\left(l_{e}\right)$ power limits $\left(P_{\max }\right.$ and $\left.P_{\min }\right)$. For each period of time $(t \in \mathscr{T})$, a constraint is added to reflect the energy capacity of the ESS units (17). Note that the model assumes that the energy capacity of the ESS is consistent with each time period used. ${ }^{5}$ The set of constraints for ESS units are:

$$
\begin{array}{r}
l_{e}^{i} \leq \sum_{t<=T} p_{t}^{i} \cdot t \leq u_{e}^{i}, \forall i \in \mathscr{E}, t \in \mathscr{T} \\
\sum_{t \in \mathscr{T}} p_{t}^{i} \cdot t=0, \forall i \in \mathscr{E} \\
u_{e}^{i}=s c_{0}^{i} \cdot u_{\max , e}^{i} \\
l_{e}^{i}=l_{\min , e}^{i}+u_{e}^{i} \\
l_{\min , e}^{i}=-u_{\max , e}^{i}
\end{array}
$$

The sum of all injections and demands (negative injections) should add to zero as per energy conservation (18). This is a transversality condition equivalent to stating that the final state of charge should be equal to the initial state of charge for all ESS units in the system $(i \in \mathscr{E})$. The initial state of charge of all ESS units will affect the available energy for the first period (19), which is equivalent to an adjustment in the limits of the ESS (20). For the planning horizon considered, it is assumed that there is no degradation in the capacity of the battery for the horizon considered (21).

Equations (17)-(21) are the specific forms of constraints that can be expressed in general form as shown in (7). An advantage of modeling the ESS like a single unit is that it is not necessary to create additional intra-period

\footnotetext{
${ }^{3}$ Different reserves can be added as part of the $A$ matrix, see e.g. (28).

${ }^{4}$ The extension to cover reactive power can be added, but for the applications envisioned, active power will be the main product.

${ }^{5}$ e.g. If energy capacity is in MWh, every time period should be hours. Technology differences can be factored in the individual ramping coefficients of the ESS units.
} 
constraints to rule out the possibility of having both a power injection and a power demand (charge) from the same ESS unit in a given period. However, this limits the efficiencies for charging and discharging to be equal.

\subsection{Renewable Energy Sources and Dynamic Information Update}

To integrate the stochastic changes in renewable generation resources, the following algorithm is used:

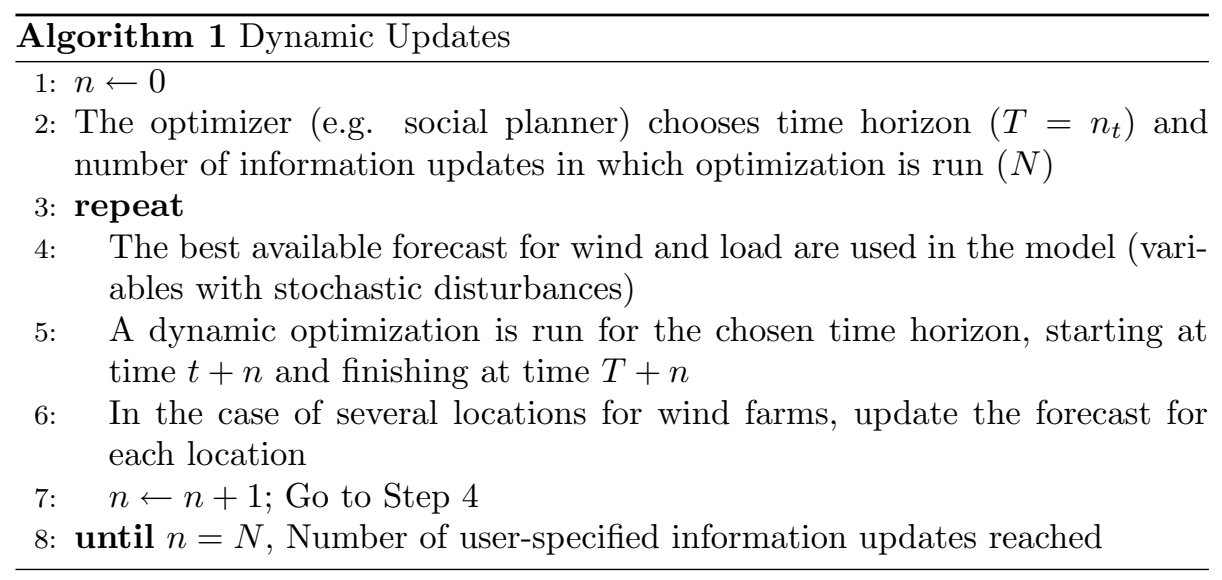

With algorithm 1 , the dynamic optimization updates information on stochastic variables on a receding horizon (rolling basis). The variables of interest to be updated are the wind forecast and the load of the system. ${ }^{6}$

The matrix of information updates for the stochastic variables (including wind speed and load forecasts) is shown in (22). The horizon is given by $T$, and the number of specified information updates ('shifts') is given by $N$.

$$
\left[W_{f}, L_{f}\right]=\left[\begin{array}{cccc}
f(t) & f(t+1) & \ldots & f(t+N) \\
f(t+1) & f(t+2) & \ldots & f(t+1+N) \\
\vdots & \vdots & \ddots & \vdots \\
f(t+T) & f(t+T+1) & \ldots & f(t+T+N)
\end{array}\right]
$$

For a single multi-period OPF optimization, only the information in one column is needed. Successive columns have the dynamic information updates. This framework was extended in the simulation implemented to allow for several ESS units in the system.

\subsection{Analytical Property Solutions}

Consider the problem stated in (1). In this section I ignore the commitment variables to study some of the properties of the solution. I posit a social planner

\footnotetext{
${ }^{6}$ If a contingency occurs, the topology to maintain the system $n-1$ secure
} 
seeking to maximize social welfare by solving an optimal power flow in an AC network with $n_{b}$ buses, $n_{t}$ time periods, $n_{g}$ generating units and $n_{e}$ ESS units. Table 2 defines the sets and variables used in this sub-problem. The order of the subindices is maintained whenever possible, and no commas are used, unless there is an operation on the index (e.g. $t+1)$.

Table 2: Nomenclature for the problem

\begin{tabular}{ll}
\hline Variable & Description \\
\hline $\mathscr{T}$ & Set of all time periods, $n_{t}$ elements. \\
$\mathscr{B}$ & Set of all buses, $n_{b}$ elements. \\
$\mathscr{G}$ & Set of generating units, $n_{g}$ elements. \\
$\mathscr{E}$ & Set of ESS units, $n_{e}$ elements. \\
$\Theta, V$ & Vector of $n_{b}$ bus voltage angles and magnitudes $\in \mathbf{x}$ \\
$P, Q$ & Vector of $n_{g}$ active and reactive power injections from generators $\in \mathbf{p}$ \\
$E, F$ & Vector of $n_{e}$ active (and possibly reactive) power injections from ESS \\
$C_{P_{i}}(\cdot), C_{Q_{i}}(\cdot)$ & Cost for $i$ active and reactive injections from generators \\
$C_{E_{i}}(\cdot), C_{F_{i}}(\cdot)$ & Cost of active and reactive injections for ESS units \\
$\pm R_{X i}^{\mathrm{ph} \pm}$ & Physical limits for active power $(X=P, E)$ for generators and ESS \\
$\pm R_{Y i}^{\mathrm{ph} \pm}$ & respectively \\
$s c_{0}^{i}$ & Physical limits for reactive power $(Y=Q, F)$ for generators and ESS \\
$l_{\min , e}^{i}, u_{\max , e}^{i}$ & respectively \\
$\rho^{t}$ & Initial State of Charge for ESS unit $i$ \\
\hline
\end{tabular}

For notational simplification, when indicated as super indices, it will refer to the set of all variables across that dimension. For example, $e^{t} \in \mathbf{e}$ will refer to all injections from ESS units in period $t ; e_{i t}$ refers to the injection from ESS unit $i$ in period $t$. The explicit form of the problem can be formulated as follows.

$$
\min _{\Theta, V, P, Q, E, F} \sum_{t \in \mathscr{T}} \rho^{t} \sum_{i \in \mathscr{G}^{t} \cup \mathscr{E}^{t}} C_{P_{i}}\left(p_{i t}\right)+C_{Q_{i}}\left(q_{i t}\right)+C_{E_{i}}\left(e_{i t}\right)+C_{F_{i}}\left(f_{i t}\right)
$$


subject to

$$
\begin{gathered}
g_{P}^{t}\left(\Theta^{t}, V^{t}, P^{t}, Q^{t}, E^{t}, F^{t}\right)=0, \quad \forall t \in \mathscr{T} \\
g_{Q}^{t}\left(\Theta^{t}, V^{t}, P^{t}, Q^{t}, E^{t}, F^{t}\right)=0, \quad \forall t \in \mathscr{T} \\
h^{t}\left(\Theta^{t}, V^{t}, P^{t}, Q^{t}, E^{t}, F^{t}\right) \leq 0, \quad \forall t \in \mathscr{T} \\
-R_{P i}^{\mathrm{ph}-} \leq p_{i t}-p_{i, t-1}^{t} \leq R_{P i}^{\mathrm{ph}+}, \forall i \in \mathscr{G}, t \in \mathscr{T} \\
-R_{Q i}^{\mathrm{ph}-} \leq q_{i t}-q_{i, t-1} \leq R_{Q i}^{\mathrm{ph}+}, \forall i \in \mathscr{G}, t \in \mathscr{T} \\
-R_{E i}^{\mathrm{ph}-} \leq e_{i t}-e_{i, t-1}^{t} \leq R_{E i}^{\mathrm{ph}+}, \forall i \in \mathscr{E}, t \in \mathscr{T} \\
-R_{F i}^{\mathrm{ph}-} \leq f_{i t}-f_{i, t-1} \leq R_{F i}^{\mathrm{ph}+}, \forall i \in \mathscr{E}, t \in \mathscr{T} \\
u_{\max , i e} \cdot\left(s c_{i, 0}-1\right) \leq \sum_{\tau<=t} e_{i \tau} \cdot \alpha \leq u_{\max , i e} \cdot s c_{i 0}, \forall i \in \mathscr{E}, t \in \mathscr{T} \\
\sum_{t \in \mathscr{T}} e_{i t} \cdot t=0, \forall i \in \mathscr{E}
\end{gathered}
$$

Each generator has a capability curve that determines the relation between the active and reactive output it can inject into the network. Since the implementation is done in MATPOWER, these capability curves can be trapezoidal. By convention, positive values of $p, q, e$ and $f$ are considered injections, while negative values are considered demands.

The equality constraints (2), (24)-(25) are explicitly defined by the power balance equations for active and reactive power.

$$
\begin{aligned}
& p_{i t}-\sum_{j \in \mathscr{B}}\left|v_{j t}\right|\left|v_{i t}\right|\left[G_{i j t} \cos \left(\theta_{i}-\theta_{j}\right)+B_{i j t} \sin \left(\theta_{i}-\theta_{j}\right)\right]=0, \quad \forall i \in \mathscr{B}, t \in \mathscr{T} \\
& q_{i t}-\sum_{j \in \mathscr{B}}\left|v_{j t}\right|\left|v_{i t}\right|\left[G_{i j t} \sin \left(\theta_{i}-\theta_{j}\right)-B_{i j t} \cos \left(\theta_{i}-\theta_{j}\right)\right]=0, \quad \forall i \in \mathscr{B}, t \in \mathscr{T}
\end{aligned}
$$

The inequality constraints defined by (3), (26) correspond to two set of branch flow limits as function of the bus voltages and angles, for the from and to flows on each branch. ${ }^{7}$ Equations (27) and (29) determine the active ramping constraints for generators and ESS units, according to their physical characteristics. Equations (28) and (30) are the equivalent conditions to (27) and (29) for the reactive variables. Equation (31) reflects the energy limits on the ESS units, taking into account the initial state of charge; $\alpha$ denotes the time period interval over which a certain power output is needed. ${ }^{8}$ Equation (32) is the specific form of the transversality condition (18), denoting that after all injections and demands into the network are taken into account, the final state of charge of the ESS should be equal to the initial state of charge. For notational purposes, it is assumed that there is only one generator per bus. The Lagrangian for the social planner problem, focusing only in active power,

\footnotetext{
${ }^{7}$ see (27) and (24) for further detail.

${ }^{8}$ The losses and efficiency in the system can be factored using this parameter as well.
} 
is then:

$$
\begin{aligned}
\mathcal{L}(\Theta, V, P, E, \lambda, \mu)= & \sum_{t \in \mathscr{T}} \rho^{t} \sum_{i \in \mathscr{G} t \cup \mathscr{E}^{t}} C_{P_{i}}\left(p_{i t}\right)+C_{E_{i}}\left(e_{i t}\right)+\sum_{t \in \mathscr{T}} \sum_{i \in \mathscr{G} t \cup \mathscr{E}^{t}} \lambda_{i t}\left(g_{P g_{i t}}-p_{i t}^{\text {net }}+P_{D i t}\right) \\
& +\lambda_{\text {other }}^{T} g_{\text {other }}+\mu_{\text {other }}^{T} h_{\text {other }} \\
& +\sum_{t \in \mathscr{T}} \sum_{i \in \mathscr{G} t} \mu_{\mathrm{ph} \mathrm{Rp_{it } ^ { + }}}\left(p_{i t}-p_{i, t-1}-R_{P i}^{\mathrm{ph}+}\right) \\
& +\sum_{t \in \mathscr{T}} \sum_{i \in \mathscr{G} t} \mu_{\mathrm{ph} R p_{i t}^{-}}\left(-p_{i t}+p_{i, t-1}-R_{P i}^{\mathrm{ph}-}\right) \\
& +\sum_{t \in \mathscr{T}} \sum_{i \in \mathscr{E}^{t}} \mu_{\mathrm{ph} e R p_{i t}^{+}}\left(e_{i t}-e_{i, t-1}-R_{E i}^{\mathrm{ph}+}\right) \\
& +\sum_{t \in \mathscr{T}} \sum_{i \in \mathscr{E}^{t}} \mu_{\mathrm{ph} R p_{i t}^{-}}\left(-e_{i t}+e_{i, t-1}-R_{E i}^{\mathrm{ph}-}\right) \\
& +\sum_{t \in \mathscr{T}} \sum_{i \in \mathscr{E}^{t}} \mu_{\mathrm{ESS} p h_{i t}^{+}}\left(\sum_{\tau \leq t} e_{i \tau} \cdot \alpha-u_{\max , i e} \cdot s c_{i 0}\right) \\
& +\sum_{t \in \mathscr{T}} \sum_{i \in \mathscr{E}^{t}} \mu_{\mathrm{ESS} p h_{i t}^{-}}\left(-\sum_{\tau \leq t} e_{i \tau} \cdot \alpha+u_{\max , i e} \cdot\left(s c_{i 0}-1\right)\right)
\end{aligned}
$$

The set of $\left\{\lambda_{i t}\right\}$ in (35) corresponds to the sequence of Lagrange multipliers for active power for each bus and time period. The multipliers $\lambda_{\text {other }}^{T}$ and $\mu_{\text {other }}^{T}$ correspond to other equality and inequality constraints not explicitly expressed here (e.g. Maximum power output per generator, $\left.P_{\max , i}\right)$. The sets $\left\{\mu_{\mathrm{ph} R p_{i t}^{+}}\right\},\left\{\mu_{\mathrm{ph} R p_{i t}^{-}}\right\},\left\{\mu_{\mathrm{ph} e R p_{i t}^{+}}\right\}$and $\left\{\mu_{\mathrm{ph} e R p_{i t}^{-}}\right\}$are the Karush-Kuhn-Tucker (KKT) multipliers on the inter-temporal ramping constraints per generator. $p_{i t}^{\text {net }}$ is defined as $p_{i t}+e_{i t}$, where negative values of $e_{i t}$ correspond to demands from the network, and positive values to injection into the network.

Theorem 1. Optimality Conditions, Social Planner Model

Let $\mathscr{F}^{*}\left(P_{D}^{t i}\right)$ denote the value of the objective function at the optimal solution as a function of the demand in bus $i$, and let $\left\{\lambda^{i t}\right\}$ denote the set of Lagrange multipliers for the power balance equation. Then, the optimal solution satisfies:

$$
\begin{aligned}
& \text { For } p_{i t} \\
& \rho^{t} \frac{\partial C_{P_{i}}\left(p_{i t}\right)}{\partial p_{i t}}+\left(\mu_{p h R p_{i t}^{+}}-\mu_{p h R p_{i, t+1}^{+}}\right)-\left(\mu_{p h R p_{i t}^{-}}-\mu_{p h R p_{i, t+1}^{-}}\right)=\lambda_{i t}=\frac{\partial \mathcal{L}}{\partial P_{D i t}}
\end{aligned}
$$

And for $e_{i t}$ :

$$
\begin{aligned}
& \rho^{t} \frac{\partial C_{E_{i}}\left(e_{i t}\right)}{\partial e_{i t}}+\left(\mu_{p h e R p_{i t}^{+}}-\mu_{p h e R p_{i, t+1}^{+}}\right)-\left(\mu_{p h e R p_{i t}^{-}}-\mu_{p h e R p_{i, t+1}^{-}}\right) \\
& +\alpha \sum_{\tau \geq t}^{n_{t}}\left(\mu_{E S S p h_{i \tau}^{+}}-\mu_{E S S p h_{i \tau}^{-}}\right)=\lambda_{i t}=\frac{\partial \mathcal{L}}{\partial P_{D i t}}
\end{aligned}
$$


The economic interpretation of the FOC's is that any additional demand can be covered by either moving a generator, (36) or moving an ESS, (37). For each one, there is an inter-temporal cost associated to moving the injection into the network, either as a ramp up, a ramp down or, in the case of ESS units, the availability of energy stored in the system. The $\lambda_{i t}$ in equations (36) and (37) measure the change in the objective value (cost) by relaxing the constraint for node $i$ and time period $t$. This shadow price is used for compensation of generators and payments from loads and is identified in the literature as the Locational Marginal Price (LMP).

Theorem 2. Let $\mu_{p h e R p_{i t}^{+}}$and $\mu_{p h e R p_{i t}^{-}}$denote the Karush-Kuhn-Tucker (KKT) multipliers for the upward and downward ramp limits in bus $i$ for period $t$, and

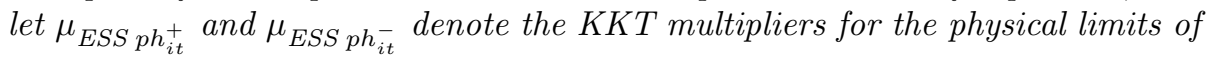
ESS units. Then

$$
\begin{aligned}
& \rho^{t+1} \frac{\partial C_{E_{i, t+1}}\left(e_{i, t+1}\right)}{\partial e_{i, t+1}}-\rho^{t} \frac{\partial C_{E_{i t}}\left(e_{i t}\right)}{\partial e_{i t}}+\left(-\mu_{p h e R p_{i t}^{+}}+2 \times \mu_{p h e R p_{i, t+1}^{+}}-\right. \\
& \left.\mu_{p h e R p_{i, t+2}^{+}}\right)-\left(-\mu_{p h e R p_{i t}^{-}}+2 \times \mu_{p h e R p_{i, t+1}^{-}}-\mu_{p h e R p_{i, t+2}^{-}}\right)- \\
& \alpha\left(\mu_{E S S p h_{i t}^{+}}-\mu_{E S S p h_{i t}^{-}}\right)=\lambda_{i, t+1}-\lambda_{i t}
\end{aligned}
$$

Therefore, in consecutive periods, the difference in nodal prices is equal to:

- The discounted difference in marginal cost of use of the ESS resource

- The inter-period shadow price differences for increasing the injection from the ESS resource (ramp up)

- The inter-period shadow price differences for increasing the charging of the ESS resource (ramp down)

- The shadow price of using the energy stored in the ESS resource

Generalizing between periods $t$ and $t+\tau$, the FOC's can be modified to obtain:

Theorem 3. the FOC's for the problem stated in (35) between periods $t$ and $t+\tau$, satisfy

$$
\begin{aligned}
& \rho^{t+\tau} \frac{\partial C_{E_{i, t+\tau}}\left(e_{i, t+\tau}\right)}{\partial e_{i, t+\tau}}-\rho^{t} \frac{\partial C_{E_{i t}}\left(e_{i t}\right)}{\partial e_{i t}}+\left(\mu_{p h e R p_{i, t+\tau}^{+}}-\mu_{p h e R p_{i, t+\tau+1}^{+}}-\right. \\
& \left.\mu_{p h e R p_{i t}^{+}}+\mu_{p h e R p_{i, t+1}^{+}}\right)-\left(\mu_{p h e R p_{i, t+\tau}^{-}}-\mu_{p h e R p_{i, t+\tau+1}^{-}}-\right. \\
& \left.\mu_{p h e R p_{i t}^{-}}+\mu_{p h e R p_{i, t+1}^{-}}\right)-\alpha \sum_{\xi=t}^{t+\tau-1}\left(\mu_{E S S p h_{i \xi}^{+}}-\mu_{E S S p h_{i \xi}^{-}}\right)=\lambda_{i, t+\tau}-\lambda_{i t}
\end{aligned}
$$

The FOC's in (39) show the optimal equilibrium condition for any two periods in which energy is to be used. The structure is similar to the aforementioned costs for the consecutive periods case, with additional terms for consecutive ramp costs in periods $t$ and $t+\tau$. 


\section{Model Calibration}

This model is applied to an illustrative case study. We use a highly modified 30 bus network (29) shown in Figure 1. The system is divided into three areas, and has been modified to represent a network with a urban area (Area 1) with a large load, high Value Of Lost Load (VOLL, (30)) and expensive sources of generation. Areas 2 and 3 represent rural areas with smaller loads, lower VOLLs and comparatively inexpensive sources of generation. An efficient economic dispatch would use the available generation capacity in the rural areas to cover their local demand and whatever demand it can cover in expensive urban areas (Area 1). The capacity of the lines transferring energy from Areas 2 and 3 to Area 1 (Lines 12, 14, 15 and 36) are constrained and therefore act as the limiting factor.

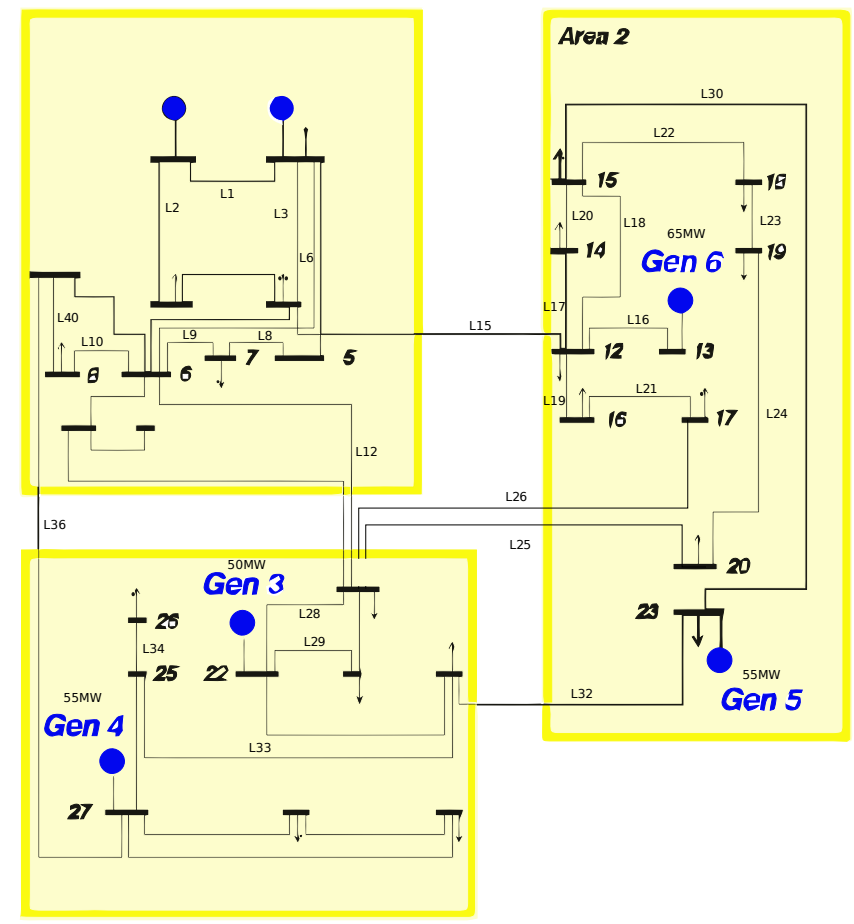

Figure 1: A One-Line-Diagram of the 30-Bus Test Network.

The information for wind availability follows the three components described by (31): 1) a set of time series data $9^{9}$ 2) an ARMA model for the prediction of wind speeds; and 3), a power curve for a wind turbine, converting a wind speed into the amount of power delivered into the network. The user provides information on the wind forecast expected for each wind location. In cases in

\footnotetext{
${ }^{9}$ In this case, with hourly data from a wind farm in New England.
} 
which the wind farms are geographically closer, the wind forecasts are likely to be similar. However, geographical averaging $((32))$ can occur due to placement of the wind farms and differences in the availability of the wind resource; in such cases, each wind location is provided with independent forecasts. Changes in the topology of the network (e.g. generator or branch outages) can be updated as more information becomes available.

The fuels included are Oil, Gas Combustion Turbines (GCT), Combined Cycle Gas turbines (CC Gas), Nuclear, Hydroelectric and Refuse (NHR) and the ESS unit(s), in case of discharge). The specifications of fuel types and available generation are shown in table 3 . The units are labeled as peaking (p), shoulder (s) or baseload (b), according to their ramping management capabilities.

Table 3: Fuel Costs and Availabilities

\begin{tabular}{|c|c|c|c|}
\hline & & $\begin{array}{l}\text { Euel Cost } \\
\$ / \mathrm{MWh})\end{array}$ & $\begin{array}{l}\text { Gen. Avail } \\
(\mathrm{MW})\end{array}$ \\
\hline Oil & (p) & 95 & 65 \\
\hline $\mathrm{GCT}$ & (p) & 80 & 45 \\
\hline CC Gas & (s) & 55 & 40 \\
\hline NHR & (s) & 5 & 65 \\
\hline Coal & (b) & 25 & 70 \\
\hline NHR & (b) & 5 & 50 \\
\hline ESS & (b) & 100 & $4-5$ \\
\hline
\end{tabular}

All cases were set to have a $T=24$ dynamic optimization horizon and $N=7$ successive periods for dynamic updates. The horizon is set for the day, while the number of updates reflects a typical range of change in operations. There were no contingencies added in any of the successive information updates, and therefore the dispatch behavior expected should be smooth, following the changes in load expected over the 24 hour optimization period. The configuration of the matrix with information updates has the form shown in (40)

$$
\left[W_{f c s t}, L_{f c s t}\right]=\left[\begin{array}{cccc}
f(7) & f(8) & \ldots & f(13) \\
f(8) & f(9) & \ldots & f(14) \\
\vdots & \vdots & \ddots & \vdots \\
f(6) & f(7) & \ldots & f(12)
\end{array}\right]
$$

The time-step units considered are hours; the wind and load forecasts are provided for $24 \times 7$ hours of the day; each shift updates the most recent information for all time periods, shifting one time period per iteration. ${ }^{10}$

\footnotetext{
${ }^{10}$ Removing the first prior time period and adding one extra time period, hence the 'shift'. Different time scales can be used, but input data needs to be consistent.
} 


\section{Case Study}

For this illustrative case, we are interested in understanding the welfare effects of distributing wind capacity vs. distributing the ESS capacity for operational purposes (21). For this purpose, the following cases are analyzed:

- Case 1: one ESS unit (40MWh energy capacity) placed close to the load center (bus 8), and one $50 \mathrm{MW}$ capacity wind farm in a rural location (bus 13)

- Case 2: (split wind capacity) two $25 \mathrm{MW}$ wind farms are placed in two apart buses (bus 13 and bus 27), with similar patterns; one 40MWh ESS unit in bus 8

- Case 3: (split ESS capacity) Two ESS units in the system (20 MWh energy capacity for each one), one close to load center (bus 8) and the other in the wind farm bus; one wind farm with 50MW capacity in bus 13

- Case 4: Two ESS units (bus 8 and bus 13, 20MWh energy capacity for each one), and two wind farms (buses 13 and 27, 25MW capacity for each one) with similar wind patterns

Case 1 provides a base case, with all the wind capacity and the ESS capacity centralized. Case 2 provides a comparison of the benefits of diversifying wind locations with respect to Case 1 . The case provides a lower bound of the benefits, using identical forecasts in the chosen locations. Case 3 allows to compare the operational costs and benefits of dividing the ESS capacity, maintaining efficiencies on a comparable basis to Case 1. Case 4 provide further incremental companions for cases 2 and 3 of complementing the geographical diversification.

The price of energy provided by all ESS units is considered identical, regardless of its closeness to load. This allows to compare cases on a similar basis. ${ }^{11}$ Additionally, the capacity of the ESS units is set to 40MWh when placed in a single location (Cases 1 and 2) and to 20MWh for each unit for multiple ESS units (Cases 3 and 4). In the multiple ESS cases, each unit differs in hourly power delivery capability, with the unit located in the Urban center being limited to $4 \mathrm{MW}$ of instant power delivery, and the ESS unit placed in the wind farm location limited to 5MW. Ramp limits are set consistent with power delivery limits (i.e. ESS units are not ramp constrained). The capacity of the wind farm is 50MW when placed in a single location (Cases 1 and 3), and 25MW in each location when two are placed in the system (Cases 2 and 4). The wind forecast for each location is provided as independent but closely correlated, with a random gaussian noise added for each location. This corresponds to a case in which farms are either located geographically close, or in zones with common wind patterns. This information is updated for each one of the shifts in successive periods $(N)$.

\footnotetext{
${ }^{11}$ In practice, location is likely play a role on technology selection, and therefore the ESS operating costs. Capital costs are not considered, see (33) for an analysis on this.
} 
While the total power available from the ESS units is low in each period, as observed in some pilots with NaS Chemical batteries ((10)), the energy capacity installed (40MWh) allows for flexibility in the usage of the resource. The pattern of wind availability is taken from historical data for New England $((31))$, to mimic the availability of wind in New York State. The load profile corresponds to historical data from the New York State Independent System Operator (NYISO).

\section{Results and ESS Management}

Figure 2 has the plot of the energy available in the ESS unit for each time period. The receding horizon is shown on a fixed axis. The time period depends on the 'shift' considered. For example, for $n=9$, the first time period is $t=10$, and the axis shows $t_{s}=t-n \rightarrow t_{s}=10-9=1$.

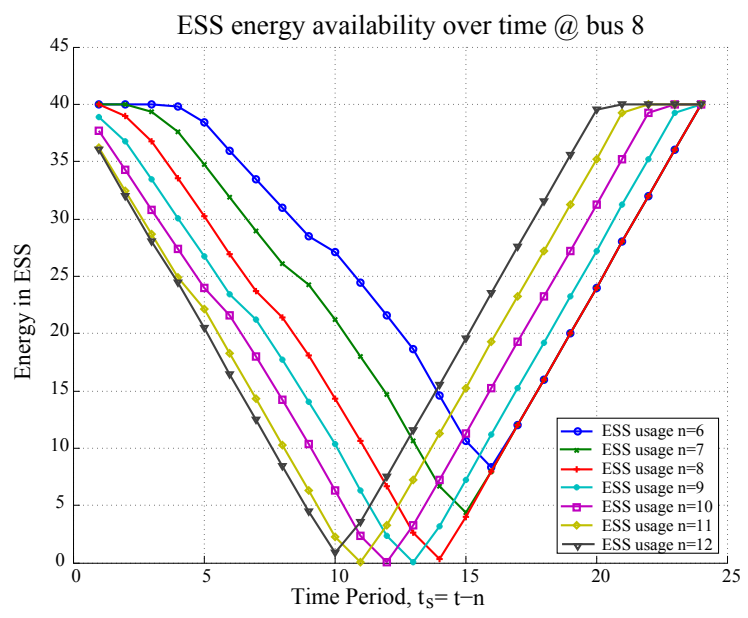

Figure 2: Energy Available from ESS unit, Case 1

Given the lack of sudden changes in the update of information for every time period, the observed ESS management follows the usage pattern expected, discharging at high load periods and starting to charge from around 11PM. In the optimization starting at 7AM, the ESS is not completely depleted of charge, and is not used for the first hours of the optimization period (7 to 10AM). The behavior hour to hour is not an exact shift, but rather a response to the most updated system conditions, due to the gaussian noise added.

By distributing the wind farms in the network (Figure 3), the optimal dispatch pattern of the ESS changes, requiring less of the installed capacity due to the decrease in wind spillage. In fact, the capacity of the ESS is not fully used in all cases, and there are idle periods during high demand hours, contrasting with the case with a single wind farm. This is due to congestion relief of lines 15 and 
36 , increasing the flow from Areas 2 and 3 to area 1, taking advantage of the more economical resources in these areas. The distribution of the ESS capacity

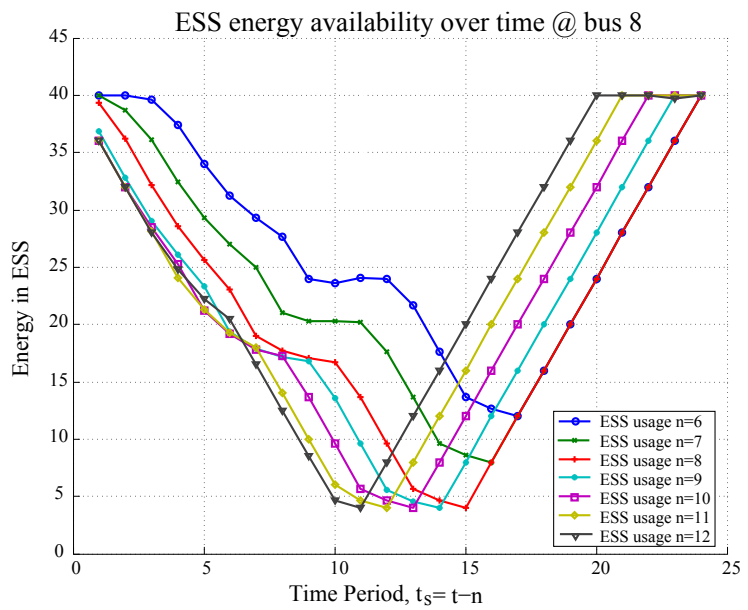

Figure 3: Energy Available from ESS unit, Case 2

-Figures 4(a) - 4(b)- leads to apparent higher usage of the energy capacity of the ESS that in Case 1, with patterns still depleting the charge during the day and charging it in the low-demand hours of the day. In this Case, the usage is constant from the moment it begins to be discharged, though the discharge rates differs between the urban and the wind sites. The second ESS is directly connected at the wind bus, which helps to offset the potential variability from this generator.

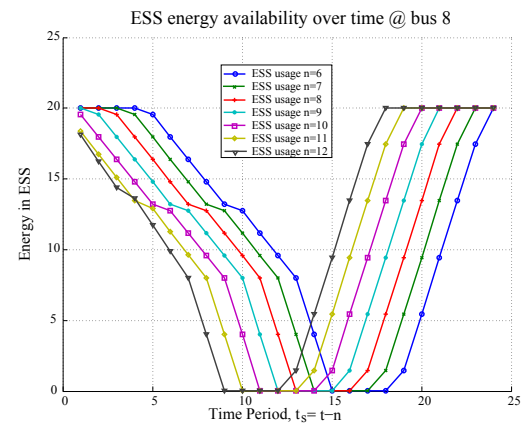

(a) Unit 1 (Bus 8)

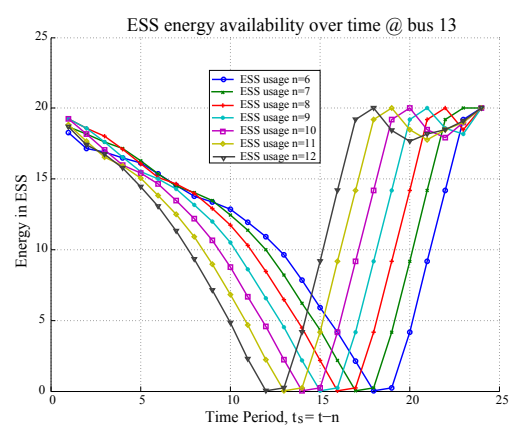

(b) Unit 2 (Bus 13)

Figure 4: Energy Available from ESS units, Case 3

Finally, the case in which the capacity is distributed for both RES and ESS 
units is shown in Figures 5(a) and 5(b). In this case, an effect that was very minor in Case 2 is amplified: there is some charging happening in periods of demand that are not low load periods (e.g. 5PM), for the ESS placed in the urban area. Analyzing the pattern of dispatch of the wind resource for this hour, it is fully utilized for the unit placed in bus 13, and the unit at bus 27 is ramping up at a pace equivalent to the charging rate of the ESS in bus 8 . While this is not a direct coupling, there is evidence of the complementarity of the two units to better use the RES available. There is also utilization of the ESS capacity starting at 6AM (refer to, for example $n=12$ ). Due to the transversality conditions imposed, though the unit discharges again, it should be fully charged (initial condition) at the end of the optimization period. ${ }^{12}$

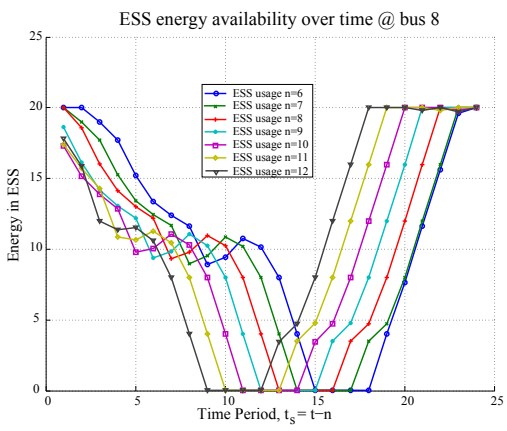

(a) Unit 1 (Bus 8)

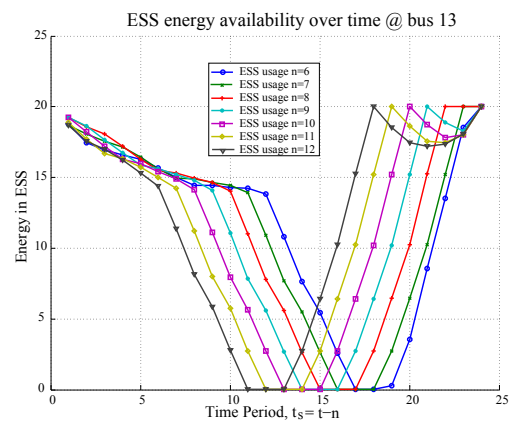

(b) Unit 2 (Bus 13)

Figure 5: Energy Available from ESS units, Case 4

\subsection{Savings and Costs in the Wholesale Market}

The analysis of the benefits of adoption of ESS and geographic distribution of capacity requires the study of the compensation for each agent in the wholesale market. Table 4 summarizes some key results for each one of the cases over a 24 hour load cycle. Due to the information updates, incorporating the changes in system conditions, the results in Table 4 show the average of each one of the quantities considered over the seven information updates, as well as the variances (in parenthesis).

The first row (1. Load Paid) shows the benefits of distributing wind capacity in a geographic area (Case 1 to Case 2), as well as the benefits of ESS adoption with Geographic Wind distribution (Case 3 to Case 4). While the deployment of an additional ESS in the system (Case 1 to Case 3 ) leads to higher customer payments, this is mainly driven by lower wind usage in this case, a paradoxical result given the ESS placement in the wind farm. The reason for this will be

\footnotetext{
${ }^{12}$ In the case of $n=12$, at 11 AM the ESS units must be fully charged.
} 
Table 4: Summary of Key Results

\begin{tabular}{|c|c|c|c|c|}
\hline & Case 1 & Case 2 & Case 3 & Case 4 \\
\hline \multirow[t]{2}{*}{ 1. Load Paid ${ }^{a}$} & 146.29 & 90.62 & 147.77 & 86.76 \\
\hline & $(9.66)$ & $(0.09)$ & $(0.01)$ & $(0.00)$ \\
\hline \multirow[t]{2}{*}{ 2. GenEne ${ }^{*}, b$} & $4,049.30$ & $4,038.80$ & $4,050.17$ & $4,037.70$ \\
\hline & $(0.28)$ & $(0.08)$ & $(0.01)$ & $(0.01)$ \\
\hline \multirow[t]{2}{*}{ 3. $\operatorname{MaxWE}^{*}, c$} & 638.69 & 639.25 & 600.00 & 919.85 \\
\hline & $(0.12)$ & $(0.14)$ & $(0.00)$ & $(0.04)$ \\
\hline \multirow[t]{2}{*}{ 4. C.Gen ${ }^{d}$} & 84.23 & 84.17 & 85.19 & 77.22 \\
\hline & $(0.00)$ & $(0.00)$ & $(0.00)$ & $(0.00)$ \\
\hline \multirow[t]{2}{*}{ 5. $\mathrm{LNS}^{e}$} & 0.00 & 0.00 & 0.00 & 0.00 \\
\hline & $(0.00)$ & $(0.00)$ & $(0.00)$ & $(0.00)$ \\
\hline \multirow[t]{2}{*}{ 6. E.disp ${ }^{f}$} & 20.96 & 19.78 & 20.21 & 12.57 \\
\hline & $(74.16)$ & $(81.74)$ & (199.48) & $(358.59)$ \\
\hline
\end{tabular}

${ }^{*} 50 \mathrm{MW}$ of Wind capacity installed. Mean for 7 runs, Variance in parenthesis; calculations over 24 hours.

a $\$ 1,000 /$ day.

${ }^{b}$ Energy Needed to cover load of day (MWh).

${ }^{c}$ Wind Energy Dispatched (MWh).

${ }^{d}$ Conventional Generation (\%).

${ }^{e}$ Load Not Served (Hours/day).

${ }^{f}$ Energy provided by ESS Unit(s).

discussed in further detail later. A significant change observed is the reduction in variance in the payments from loads by distributing the wind capacity (Case 1 to Case 2). The geographic distribution of ESS provides even lower variances. This is a consistent rationale for ESS utilization in operations, one of the reasons for the Vanadium redox battery in Ohio being coupled to a coal plant. The average amount of energy needed to cover the demand of the day (second row), shows a similar trend to the load paid, with expected decreases as wind capacity and ESS capacity is decentralized. Additionally, the average amounts of wind accommodated in the system tend to increase in a consistent manner, with the same exception as before (distribution of ESS capacity actually leads to a $6 \%$ decrease in the amount of wind in the system). This causes a decrease in the use of conventional generation (row 4). Row 5 provides explanation for the reason why the the distribution of ESS capacity (Case 3) leads to lower wind usage and higher payments from customers: the total ESS usage actually decreases when the capacity is split into two locations. While the reason for putting ESS capacity close to the wind source would presume higher wind (and ESS) usages, the splitting of the ESS capacity actually induces lower total average utilization of both resources. In the simulated cases, it is actually more beneficial to place the same ESS capacity close to the load. The important lesson here is that the role that location plays on ESS and wind energy outputs follows a non-linear relation. Therefore, policies to implement and couple wind farms with storage systems need to account for congestion and demand factors, to optimally place 


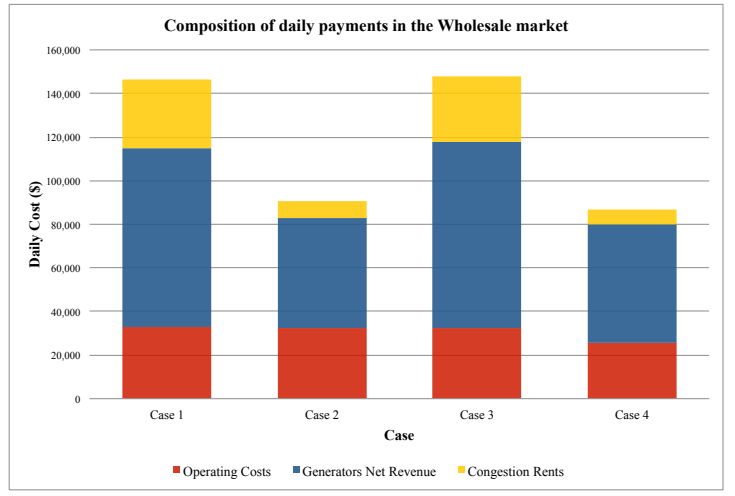

Figure 6: Payments in the Wholesale Market

and price this capacity. ${ }^{13}$

Figure 6 summarizes the average payments over 24 hours for each one of the cases considered. While the operational costs are similar in all cases, the payments from loads have clear distinctions, due to price discrimination observed in the network caused by congestion. Case 4, with the lowest payments from customers, still allows for positive transfers to transmission for network investment.

\subsection{Operations and Conventional Fleet Dispatches}

An advantage provided by the use of ESS is the possibility to service additional loads in periods of low demand, and therefore lower congestion in the network (time arbitrage). Figure 1 shows the mean fuel composition used to service the same load profile in Cases 1 to 4 . The dispatches shown correspond to the average dispatch observed over the 7 information updates simulated. In all cases, Gas Combustion Turbines (gct) and oil are not used for covering the load. This is due to the availability of cheaper sources of generation (including wind), lack of congestion in the network and overall low demand level.

The main fuels used are Nuclear, hydro and refuse (nhr, as baseload), Coal (for load following) and wind. In Cases 1 and 3, there is some utilization of the Combined Cycle (cc) gas capacity, while Cases 2 and 4 replace this fuel away completely. Total ESS dispatches are shown as a thick line in the plots. In cases where this line is below the area indicating all generation, the difference between the upper area limit and the line corresponds to charging periods for the ESS unit(s). Analogously, cases in which the 'ess' line is above the total fuel area correspond to network injections from the ESS unit(s). ESS units are used to cover part of the peak demand in all cases, while charging is done at low demand periods, as expected. The composition of the three main fuels is

\footnotetext{
${ }^{13}$ The nonlinear effects also have repercussion in light of the investments needed to modernize the electricity grid, and the environmental consequences of these investments $((34))$.
} 

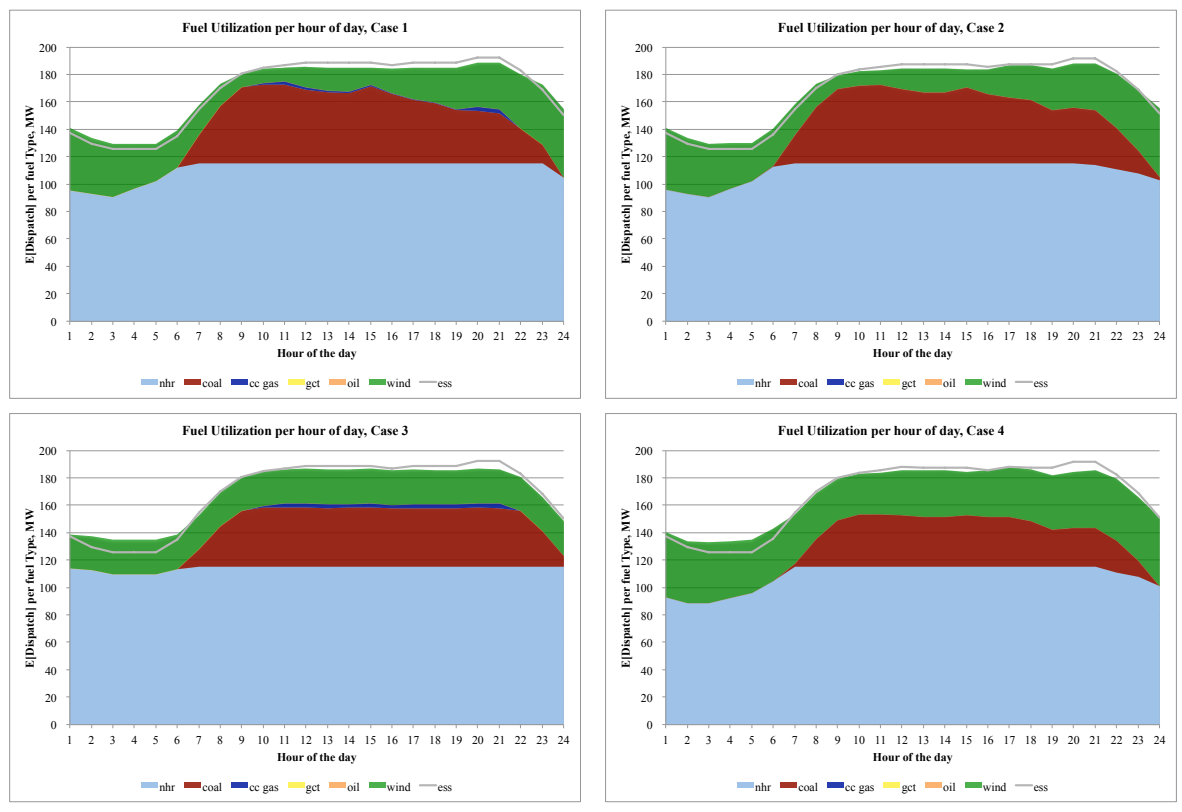

Figure 7: Generation Dispatch by Fuel Type

close in percent participation in the four cases. Case 3 is the only situation in which nhr participation is 3\% higher than the average of the three remaining cases. On the other hand, coal has the lowest participation in the generation portfolio for Case 3 (distributed ESS, single wind) and Case 4 (Distributed ESS and wind). It is remarkable the extent to which distributing ESS units in the system (Case 3 ) leads to a very smooth operation of the baseload units ('nhr'). In fact, for both Cases 3 and 4, the operation of all the generation fleet does not witness sudden changes hour to hour (in average). Taking into account that no ramping costs are included in the objective function, this is an interesting result from the point of view of the utilization of ESS units. It means that the wear-and-tear cost of the conventional generation fleet can be decreased by using these resources. Such investments will then have implications from the policy standpoint if explicit ramping markets are developed as another ancillary service $((35 ; 36))$.

The extent to which ESS units in the network provide support as grid resources is not clear cut in the simulated cases. Figure 8 compares the total dispatches net of wind for all cases. The distribution of wind in the system (comparing Case to 1 to Case 2) does not lead to adjustments of the conventional generation schedule, with almost overlapping total dispatch. The distribution of the ESS capacity (Case 3) however leads to overall higher dispatches at low demand periods (e.g. early hours of the day), and lower dispatches at peak periods. Distributing the wind capacity, joint with the ESS capacity (Case 4) shifts down the total dispatch from conventional sources due to the aforementioned 
increase on the usable wind capacity. This outcome, from the perspective of increasing wind dispatches, is a positive, if anticipated outcome: the distribution of the wind resource, and the dispatch of storage mechanisms (both close to load centers and coupled with the wind farms) are supporting mechanisms for better utilization of the RES.

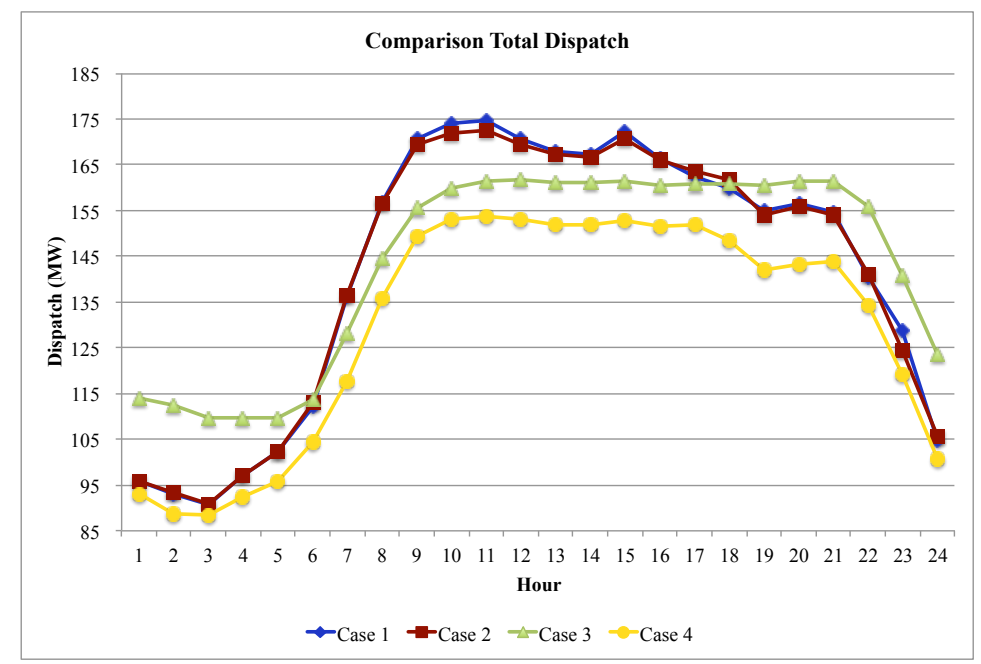

Figure 8: Comparison of Dispatches

The effect on prices is very dependent on the location. In the 30-bus network, there are potentially 30 different prices. In the simulations performed, there are approximately 10 clusters of prices observed during the day, with some separation as demand increases over the day. To simplify the analysis of prices, the simple arithmetic mean of prices over the 30 buses is calculated for the four cases simulated. Figure 9 plots the average price for all cases, giving an equal weight to all 30 buses in the system. The distribution of the wind capacity leads to lower average prices on the system, with average prices in the neighborhood of the cost of coal generation (Cases 2 and 4). The average prices for the other cases at peak hours are close to the marginal cost of combined cycle gas turbines $(\$ 55 / \mathrm{MWh})$.

It is important to note that this analysis is based on short run cost for generators. Therefore, it does not include considerations regarding the adequacy of prices to recover the cost of capital of the generating companies ("Missing Money" problem (37)).

\section{Conclusion}

This paper proposes a multiple period optimization framework to evaluate the optimal interaction of Energy Storage Systems (ESS) and Renewable Energy Sources (RES). The formulation is applied to a case study analyzing 1) the 


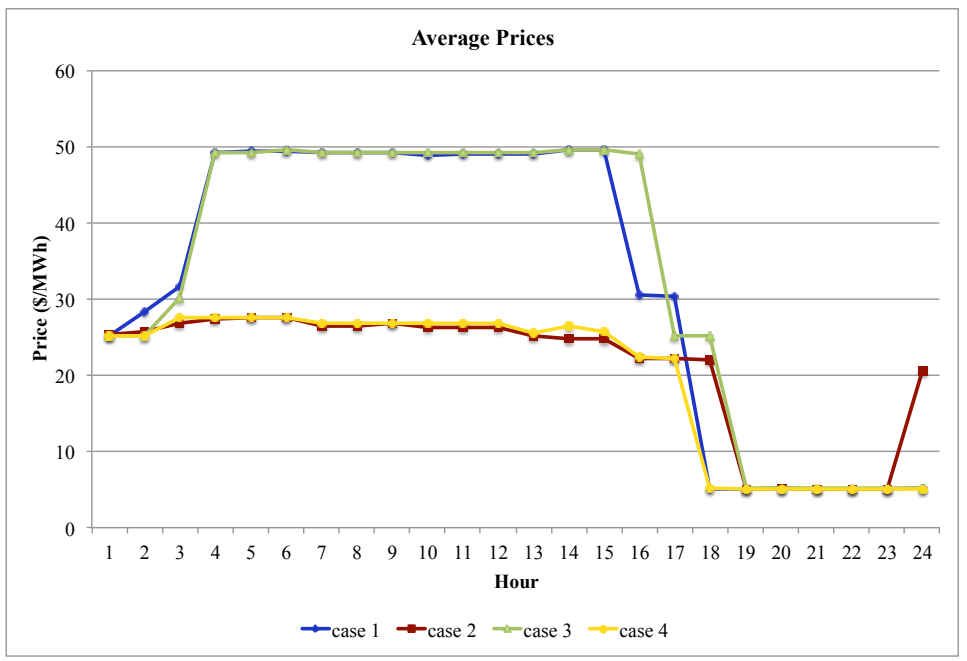

Figure 9: Average Prices Over a Day

optimal dispatch of generating units to cover a given load profile demand, 2) the welfare effects and operating costs, 3) the nodal prices and 4) the symbiotic effects between ESS and RES on a test system.

The system has dynamic updates on the conditions of the system to account for topological and operating condition changes; this is akin to incorporating the information from Phasor Measurement Units (PMU's (38; 39)) in the operation of the system, as data becomes available. The solution comes from an optimization using a primal-dual interior point method (PDIPM, (40)). The cases studied evaluate the effects of wind capacity distribution in locations with similar wind patterns, and placement of the same energy storage capacity close to load centers vs. dividing the ESS capacity in half between load center capacity and capacity close to one of the wind sites. The simulations show a very positive effect in the distribution of wind capacity, even in cases in which the forecasts for each wind site are highly correlated. The decrease in payments for loads sees reduction up to $40 \%$ in the disbursements from consumers compared to a case with a single wind site and a single ESS operating close to demand centers. There is also evidence of more effective usage of the wind capacity coupled with ESS units for the conditions simulated in cases when all ESS capacity is placed close to the main load centers. The computational complexity of this problem suggests a further research direction in the analysis of sensitivity to different numerical solvers, besides PDIPM. Though a reduced network is used, and the magnitudes observed are likely to be very different in real systems, the directions of the changes are indicative of some the effects that could be seen when further policies are rolled out favoring ESS usage. This provides a good signal for storage capacity available in the battery of cars with plug-in capabilities and a Vehicle to Grid (V2G) infrastructure in the distribution network. 


\section{Acknowledgments}

This research was supported by the US Department of Energy (DOE) and by the Power Systems Engineering Research Center (PSERC). I am very grateful to Ray Zimmerman, Tim Mount, Jon Conrad, Bob Thomas, Carlos Murillo and Dick Schuler for their useful suggestions. The author is responsible for all conclusions presented in the paper, and the views expressed have not been endorsed by the sponsoring agencies.

\section{References}

\section{References}

[1] L. Li, S. Kim, W. Wang, M. Vijayakumar, Z. Nie, B. Chen, J. Zhang, G. Xia, J. Hu, G. Graff, J. Liu, Z. Yang, A Stable Vanadium Redox-Flow Battery With High Energy Density For Large-Scale Energy Storage, Advanced Energy Materials 1 (3) (2011) 394-400. doi:10.1002/aenm.201100008.

URL http://dx.doi.org/10.1002/aenm.201100008

[2] B. Turker, S. A. Klein, E.-M. Hammer, B. Lenz, L. Komsiyska, Modeling A Vanadium Redox Flow Battery System For Large Scale Applications, Energy Conversion and Management 66 (0) (2013) 26 - 32. doi:10.1016/j.enconman.2012.09.009.

URL http://www.sciencedirect.com/science/article/pii/ S0196890412003597

[3] NERC, Reliability Standards for the Bulk Electric Systems of North America, North American Electric Reliability Corporation, 3353 Peachtree Road NE Suite 600, North Tower, Atlanta, GA 30326, 2013.

URL http://www.nerc.com/docs/standards/rs/ Reliability \_Standards $\backslash$ Complete $\backslash$ SSet.pdf

[4] C. R. Knittel, The Adoption Of State Electricity Regulation: The Role Of Interest Groups*, The Journal of Industrial Economics 54 (2) (2006) 201-222. doi:10.1111/j.1467-6451.2006.00280.x. URL http://dx.doi.org/10.1111/j.1467-6451.2006.00280.x

[5] J. Price, A. Sheffrin, Adapting California's Energy Markets To Growth In Renewable Resources, In: Power and Energy Society General Meeting, 2010 IEEE, 2010, pp. 1 -8. doi:10.1109/PES.2010.5589598.

[6] K. F. Forbes, M. Stampini, E. M. Zampelli, Do Policies To Encourage Wind Energy Inadvertently Pose Challenges To Electric Power Reliability? Evidence From The 50Hertz Control Area In Germany, The Electricity Journal 25 (9) (2012) 37 - 42. doi:10.1016/j.tej.2012.10.012.

URL http://www.sciencedirect.com/science/article/pii/ S1040619012002497 
[7] V. Buehner, B. Buchholz, Provision Of Ancillary Services By RES, in: CIGRE (Ed.), CIGRE 2010, no. C6-116 in 2010, CIGRE, 21, rue d'Artois, F75008 Paris, 2010, pp. 1-8.

[8] M. van der Meijden, I. Tigchelaar, F. Spaan, P. Jacobs, Long-Term Grid Planning In The Netherlands, in: CIGRE (Ed.), CIGRE 2010, no. C1-303 in 2010, CIGRE, 21, rue d'Artois, F75008 Paris, 2010, pp. 1-8.

[9] S. Borenstein, The Private And Public Economics Of Renewable Electricity Generation, Journal of Economic Perspectives 26 (1) (2012) 67-92. URL http://www.aeaweb.org/articles.php?doi=10.1257/jep.26.1.67

[10] K. Tanaka, J. Yoshinaga, N. Kobayashi, The Sodium Sulfur Battery For Utility-Scale Applications, in: CIGRE (Ed.), CIGRE 2008, no. C6-302 in 2008, CIGRE, 21, rue d'Artois, F75008 Paris, 2008, pp. 1-8.

[11] T. D. Mount, A. Lamadrid, S. Maneevitjit, R. J. Thomas, R. Zimmerman, A Symbiotic Role For Plug-In Hybrid Electric Vehicles In An Electric Delivery System, in: Proceedings of the 22nd Rutgers Western Conference, Monterey, CA, 2009.

[12] P. L. Joskow, Creating A Smarter U.S. Electricity Grid, Journal of Economic Perspectives 26 (1) (2012) 29-48.

URL http://www.aeaweb.org/articles.php?doi=10.1257/jep.26.1.29

[13] P. Joskow, C. Wolfram, Dynamic Pricing Of Electricity, American Economic Review 102 (3) (2012) 381-385, iD: 798695574.

URL http://www.aeaweb.org/dev/jarrod/articles\_dev/ articles.php?doi=10.1257/aer.102.3.381

[14] J. Carpentier, Contribution A L'etude Du Dispatching Economique, Bulletin de la Societe Francaise des Electriciens 3 (1962) 431-447.

[15] C. Wang, S. Shahidehpour, Optimal Generation Scheduling With Ramping Costs, Power Systems, IEEE Transactions on 10 (1) (1995) 60 -67. doi:10.1109/59.373928.

[16] H. Outhred, A Review Of Electricity Industry Restructuring In Australia, Electric Power Systems Research 44 (1) (1998) 15 - 25. doi:DOI: 10.1016/S0378-7796(97)01210-8.

URL http://www.sciencedirect.com/science/article/B6V303TW320D-3/2/a8ca131ef5cd3be4694b3d40d706c402

[17] R. Karki, P. Hu, R. Billinton, A Simplified Wind Power Generation Model For Reliability Evaluation, Energy Conversion, IEEE Transactions on 21 (2) (2006) 533 - 540. doi:10.1109/TEC.2006.874233.

[18] R. Kamat, S. Oren, Two-settlement systems for electricity markets under network uncertainty and market power, Journal of Regulatory Economics 25 (1) (2004) 5-37. 
URL http://econpapers.repec.org/RePEc:kap:regeco:v:25:y:2004: $i: 1: p: 5-37$

[19] A. Keane, M. Milligan, C. J. Dent, B. Hasche, C. D'Annunzio, K. Dragoon, H. Holttinen, N. Samaan, L. Soder, M. O'Malley, Capacity value of wind power, Power Systems, IEEE Transactions on 26 (2) (2011) 564-572. doi:10.1109/TPWRS.2010.2062543.

[20] P. Joskow, J. Tirole, Reliability and competitive electricity markets, The RAND Journal of Economics 38 (1) (2007) pp. 60-84.

URL http://www.jstor.org/stable/25046292

[21] NREL, Eastern wind integration and transmission study, Tech. rep., EnerNex Corporation, The National Renewable Energy Laboratory, 1617 Cole Boulevard, Golden, Colorado 80401 (January 2010).

[22] B. C. Lesieutre, R. J. Thomas, T. D. Mount, Identification of load pockets and market power in electric power systems, Decis. Support Syst. 40 (2005) 517-528. doi:http://dx.doi.org/10.1016/j.dss.2004.09.010.

URL http://dx.doi.org/10.1016/j.dss.2004.09.010

[23] E. T. Mansur, Measuring welfare in restructured electricity markets, The Review of Economics and Statistics 90 (2) (2008) 369-386.

URL http://ideas.repec.org/a/tpr/restat/v90y2008i2p369386.html

[24] R. D. Zimmerman, C. E. Murillo-Sanchez, R. J. Thomas, Matpower: Steady-state operations, planning, and analysis tools for power systems research and education, Power Systems, IEEE Transactions on 26 (1) (2011) 12 -19. doi:10.1109/TPWRS.2010.2051168.

[25] A. Monticelli, M. V. F. Pereira, S. Granville, Security-constrained optimal power flow with post-contingency corrective rescheduling, Power Systems, IEEE Transactions on 2 (1) (1987) 175-180. doi:10.1109/TPWRS.1987.4335095.

[26] R. Baldick, The generalized unit commitment problem, Power Systems, IEEE Transactions on 10 (1) (1995) 465 -475. doi:10.1109/59.373972.

[27] A. Wood, B. Wollenberg, Power Generation, Operation and Control, 2nd Edition, Wiley Interscience, 1996.

[28] J. Condren, T. Gedra, P. Damrongkulkamjorn, Optimal power flow with expected security costs, Power Systems, IEEE Transactions on 21 (2) (2006) 541-547. doi:10.1109/TPWRS.2006.873114.

[29] R. Ferrero, S. Shahidehpour, V. Ramesh, Transaction analysis in deregulated power systems using game theory, Power Systems, IEEE Transactions on 12 (3) (1997) 1340 -1347. doi:10.1109/59.630479. 
[30] C. K. Woo, R. L. Pupp, T. Flaim, R. Mango, How much do electric customers want to pay for reliability; new evidence on an old controversy, Energy Systems and Policy 15:2 (1991) Pages: 145-159, iD: 4434610247.

[31] C. L. Anderson, J. B. Cardell, Reducing the variability of wind power generation for participation in day ahead electricity markets, in: HICSS '08: Proceedings of the 41st Annual Hawaii International Conference on System Sciences, IEEE Computer Society, Washington, DC, USA, 2008, p. 178. doi:http://dx.doi.org/10.1109/HICSS.2008.368.

[32] M. Milligan, K. Porter, E. DeMeo, P. Denholm, H. Holttinen, B. Kirby, N. Miller, A. Mills, M. O'Malley, M. Schuerger, L. Soder, Wind power myths debunked, Power and Energy Magazine, IEEE 7 (6) (2009) 89-99. doi:10.1109/MPE.2009.934268.

[33] A. J. Lamadrid, T. Mount, Ancillary Services In Systems With High Penetrations Of Renewable Energy Sources, The Case of Ramping, Energy Economics 34 (6) (2012) 1959 - 1971. doi:10.1016/j.eneco.2012.08.011. URL http://www.sciencedirect.com/science/article/pii/ S0140988312001818

[34] L. Fan, B. F. Hobbs, C. S. Norman, Risk aversion and $\mathrm{co}_{2}$ regulatory uncertainty in power generation investment: Policy and modeling implications, Journal of Environmental Economics and Management 60 (3) (2010) 193 - 208. doi:10.1016/j.jeem.2010.08.001.

URL http://www.sciencedirect.com/science/article/pii/ S009506961000080X

[35] L. Xu, D. Tretheway, Flexible ramping products, Tech. rep., California ISO (2012).

URL http://www.caiso.com/Documents/SecondRevisedDraftFinalProposalFlexibleRampingProduct.pdf

[36] N. Navid, G. Rosenwald, Market solutions for managing ramp flexibility with high penetration of renewable resource, Sustainable Energy, IEEE Transactions on 3 (4) (2012) 784-790. doi:10.1109/TSTE.2012.2203615.

[37] T. Mount, S. Maneevitjit, A. Lamadrid, B. Thomas, R. Zimmerman, The hidden system costs of wind generation in a deregulated electricity market, The Energy Journal 33 (1) (2012) 161-186.

[38] A. Phadke, J. Thorp, M. Adamiak, A new measurement technique for tracking voltage phasors, local system frequency, and rate of change of frequency, Power Apparatus and Systems, IEEE Transactions on PAS-102 (5) (1983) 1025-1038. doi:10.1109/TPAS.1983.318043.

[39] M. He, V. Vittal, J. Zhang, Online dynamic security assessment with missing pmu measurements: A data mining approach, Power Systems, IEEE Transactions on PP (99) (2013) 1-9. doi:10.1109/TPWRS.2013.2246822. 
[40] S. Granville, Optimal reactive dispatch through interior point methods, Power Systems, IEEE Transactions on 9 (1) (1994) 136-146. doi:10.1109/59.317548. 
- We model a electricity system with high penetration of renewable energy sources (RES).

- We analyze the optimality conditions when using energy storage systems (ESS).

- We calibrate the network with realistic data for wind penetrations close to $15 \%$.

- The placement of ESS can lead to less RES usage, depending on congestion.

- The benefits to consumers are dependent on the effective MWh of RES dispatched. 